\title{
Accounting for Context beyond Domain: An Authentic Practice-based Framework for Advancing Personal Epistemology Research
}

\author{
Kacey Beddoes (corresponding author) \\ Department of Sociology \\ University of Massachusetts Lowell \\ Lowell, MA 01854 USA \\ E-mail: kacey_beddoes@uml.edu \\ Devlin Montfort \\ School of Chemical, Biological, and Environmental Engineering \\ Oregon State University \\ Corvallis, OR 97330 USA \\ E-mail: devlin.montfort@oregonstate.edu
}

\author{
Shane Brown \\ School of Civil and Construction Engineering \\ Oregon State University \\ Corvallis, OR 97330 USA \\ E-mail: shane.brown@oregonstate.edu
}

Received: June 21, 2017 Accepted: July 6, 2017 Published: July 26, 2017

doi:10.5296/ijld.v7i3.11430 URL: https://doi.org/10.5296/ijld.v7i3.11430

\begin{abstract}
This article presents a practice-based framework for personal epistemology (PE) research that advances recent efforts to broaden personal epistemology research. The framework accounts
\end{abstract}




\section{Macrothink}

International Journal of Learning and Development

ISSN 2164-4063 2017, Vol. 7, No. 3

for empirical experiences and also contributes to on-going theoretical efforts to expand personal epistemology research. Building on the "practice turn" that other fields have taken and learned from, the purpose of this article is four-fold. First, it offers a conceptual framework that addresses theoretical and empirical limitations of personal epistemology as it is currently studied. Second, it advances PE research by highlighting the importance of heretofore ignored facets of PE, namely communities of practice, context, epistemic practices, and identity. Third, it advances PE research by adding to on-going conversations about the interrelatedness of dimensions of personal epistemologies. Fourth, it lays out a research agenda for personal epistemology research and concomitant methodological considerations, which have not yet received significant attention from PE researchers.

Keywords: higher education, personal epistemology, epistemic practices, communities of practice, workplace, industry, engineering 


\section{Introduction: Origins of a Practice-Based Framework}

This article presents a practice-based framework for personal epistemology (PE) research that is grounded in authentic contexts. The proposed framework resulted from years of effort to study and make sense of engineers' personal epistemologies. It developed out of a combination of empirical research and theoretical concerns. Specifically, a realization that current personal epistemology literature could not adequately explain or conceptualize what we were seeing our data, and a recognition that if any sense was to be made of our data, it had to include deep and broad understanding of participants' contexts and experiences that were shaping their responses. It was observed that personal epistemologies could only be understood in context, through epistemic practices, and alongside identity. In proposing this framework for future research, this article answer calls to address the limitations of PE research by expanding conceptualizations of personal epistemology and epistemic cognition in new ways (Barzilai \& Zohar, 2014; Chinn, Buckland, \& Samarapungavan, 2011).

Thus, the framework accounts for empirical experiences and also contributes to on-going theoretical efforts to expand personal epistemology research. Building on the "practice turn" that other fields have taken and learned from, the purpose of this article is four-fold. First, it offers a conceptual framework that addresses theoretical and empirical limitations of personal epistemology as it is currently studied. Second, it advances PE research by highlighting the importance of heretofore ignored facets of PE, namely communities of practice, context, epistemic practices, and identity. Third, it advances PE research by adding to on-going conversations about the interrelatedness of dimensions of personal epistemologies. Fourth, it lays out a research agenda for personal epistemology research and concomitant methodological considerations, which have not yet received adequate attention from PE researchers.

\section{Theoretical Background: Personal Epistemology and Communities of Practice}

\subsection{Personal Epistemology}

Personal epistemology research examines people's understandings of knowledge and knowing (Hofer \& Pintrich, 1997). However, there is a lack of consensus on what exactly personal epistemology is. We define personal epistemology as "a collection of stances taken on issues of knowledge and knowing" (see Montfort, Brown, \& Shinew (2014) and Beddoes, Montfort, \& Brown (2017) for detailed explanations of how this definition relates to previous literature). We define stances as "rhetorical responses to specific prompts." In addition to "personal epistemology", the literature referenced in this article utilizes various other terminology, including "epistemic cognition" (e.g., Chinn, Buckland, \& Samarapungavan, 2011) and "epistemic beliefs" (e.g., Bråten, Britt, Strømso, \& Rouet, 2011). In this article, PE is conceptualized as one instantiation of the broader category of "epistemic cognition", and "epistemic beliefs" are understood as one piece of PE.

Studies of personal epistemology primarily fall into one of three categories. The first category is concerned with the dimensions of personal epistemologies, and the ways in which those dimensions may be interrelated (Bråten et al., 2011; Buehl, 2008; Hofer, 2000; 
Schommer-Aikins, 2004; Schommer, 1994). This body of work generally recognizes four dimensions of knowledge and knowing (source, certainty, justification, and structure) (Hofer, 2004). The second category is concerned with stages of development of personal epistemologies (Baxter Magolda, 1992; Belenky, Clinchy, Goldberger, \& Tarule, 1986; Carberry, Ohland, \& Swan, 2010; Jehng, Johnson, \& Anderson, 1993; King \& Kitchener, 1994; King \& Magun-Jackson, 2009; Kuhn, Cheney, \& Weinstock, 2000; Kuhn \& Weinstock, 2002; Pavelich \& Moore, 1996; Perry, 1970; Schommer-Aikins, 2002; Wise, Lee, Litzinger, Marra, \& Palmer, 2004). The third category of research is concerned with domains and whether PE should be considered domain-general or domain-specific (Buehl \& Alexander, 2005; Buehl, Alexander, \& Murphy, 2002; DeBacker et al., 2008; Elby, 2001; Hammer \& Elby, 2002, 2003; Hofer, 2000; Lising \& Elby, 2005; Louca, Elby, Hammer, \& Kagey, 2004; Mason, 2002; Muis, Bendixen, \& Haerle, 2006; Palmer \& Marra, 2004; Wood \& Kardish, 2002; Yerdelen-Damar, Elby, \& Eryilmaz, 2012). Most researchers now agree that PE is domain-specific. A more detailed discussion of each of these categories can be found in Beddoes, Montfort, \& Brown (2017).

\subsection{Communities of Practice}

To date, the PE research synthesized above has proceeded entirely apart from communities of practice literature. Inclusion of it here is the first attempt to bring the theoretical framework into conversation with $\mathrm{PE}$ research. The communities of practice $(\mathrm{CoP})$ construct was developed as a theoretical framework to explain how people learn, create meaning, and shape their identities within a community or organization (Wenger, 1998). In this social or situated approach, knowledge is understood as an individual's meaningful practices and role within a particular community. Learning is therefore redefined as changes in those practices (Sawyer \& Greeno, 2009).

The CoP framework bounds knowledge, practices, and identity together such that they are inseparable from one another (Lave \& Wenger, 1991; Wenger, 1998; Wenger, McDermott, \& Snyder, 2002). CoP emerged in the 1990s and is reflective of the "practice turn" seen in other fields as well (Schatzki, Knorr Cetina, \& Von Savigny, 2001). While CoP literature has not addressed personal epistemology specifically, it does address epistemological issues related to practices (Wenger, 1998, pp. 101-102), and other literature has linked identity to PE in various ways (e.g., Belenky et al., 1986). For our purposes, the significance of CoP lies in the ways it highlights the central influential role that everyday practices play in shaping knowledge, identity, and learning. As elaborated below, practice and identity have been missing pieces of $\mathrm{PE}$ research, but are necessary to understand PE.

\section{An Authentic Practice-Based Framework}

Most PE research does not account for authentic, real-world, contexts, and approaches personal epistemology as if it can be understood in isolation. In contrast, Figure 1 depicts a practice-based framework in which personal epistemology must be understood in relation to a community of practice that shapes context, epistemic practices, and identities. Table 1 defines each component of the framework. 


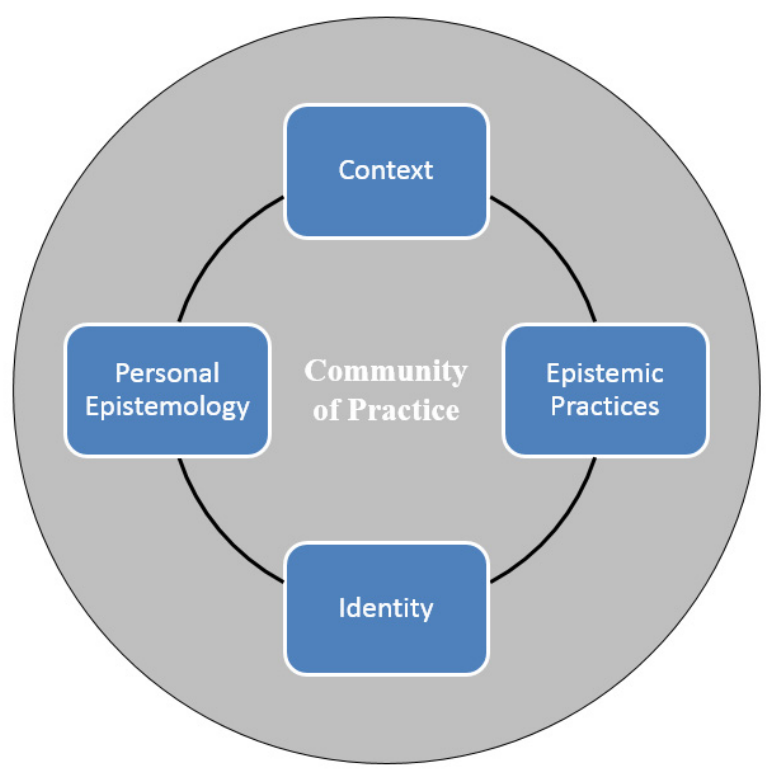

Figure 1. Framework for Practice-based PE Research

Table 1. Definitions of Framework Components

\begin{tabular}{ll}
\hline Component & Definition \\
\hline Context & Authentic milieu in which people work and live \\
Epistemic practices & $\begin{array}{l}\text { "Areas of action involved in the gathering, constitution, and implementation of" } \\
\text { knowledge and information (adapted from Calvert-Minor, 2011, p. 355) } \\
\text { "Dynamic self-understandings and self-definitions used to structure, direct, give } \\
\text { Identity }\end{array}$ \\
meaning to and present the self" (Schachter \& Rich, 2011, p.223) \\
$\begin{array}{l}\text { Collection of discursive stances taken on issues of knowledge and knowing } \\
\text { (Montfort et al., 2014) }\end{array}$ \\
\hline
\end{tabular}

\subsection{Context}

As noted, one of the key debates in PE research has centered on the extent to which personal epistemologies are domain-general or domain-specific. Barzilai and Zohar (2014) summarize the state of the field thusly: "Awareness of the importance of examining the context of epistemic thinking has risen in recent years. However, researchers of personal epistemology construe the role of context in substantially different ways" (p. 26). Many leading researchers now believe that studying PE as if it were domain-general is problematic (Barzilai \& Zohar, 2014; Montfort, Brown, \& Shinew, 2014). They acknowledge the domain-specificity of personal epistemologies and suggest that assuming generalized PE from limited data explains 
the problems that have been encountered with validity and prediction of quantitative measures (Greene, Torney-Purta, \& Azevedo, 2010; Limón Luque, 2003; Muis et al., 2006). Indeed, the most successful quantitative studies of PE have been specific to a single academic domain, such as math or physics (Franco et al., 2012; Greene et al., 2010). At an even more specific scale, the need for contextual understanding of PE is captured to some extent in the view of PE as "resources" mobilized in specific contexts for specific purposes (diSessa, Elby, \& Hammer, 2002; Elby \& Hammer, 2001; Hammer \& Elby, 2002; Louca, Elby, Hammer, \& Kagey, 2004).

However, even that work advocating domain-specificity has almost always equated domain with discipline, and context with topic, not delving deeper into authentic context-specificity within a domain. There are several studies that examine specific topics within a discipline (Bråten et al., 2009; Stahl \& Broome, 2007; Trautwein \& Lüdke, 2007), as well as topics that span disciplines, such as multiple text comprehension (Bråten et al., 2011). Yet, even these studies do not account for the authentic context in which participants live their daily lives or experience the interviews. Instead, "context" is used to mean the topic or subject of a question posed to survey or interview participants (e.g., Elby \& Hammer, 2001). More authentic, or "naturalistic" contexts have been studied, but still only in school settings (e.g., Hogan, 1999).

The scant attention authentic contexts have received is a problem because our research revealed that much more fine-grained and nuanced understandings of real-world context are needed in order to more accurately understand what participants are talking about when they are asked about personal epistemologies. The importance of understanding participants' contexts emerged repeatedly over the course of a three-year research project. It was clear that participants' discussions of their personal epistemologies were deeply rooted in the particulars of their work contexts. What at first appeared to be a methodological challenge clarified into a theoretical barrier of existing PE research. Indeed, without a deep understanding of their work lives, information vital for interpreting their personal epistemologies was missing. The practicing engineers we interviewed had all received degrees in one domain (civil engineering); yet, the context of their work lives varied drastically. Understanding PE as "domain" (read discipline) specific was not adequate to account for all the variation we observed within a single domain of civil engineering. Even within a narrower content area of civil engineering, such as structural design, we observed fundamental and pervasive differences arising from authentic contexts.

Such variation is a leading reason why the communities of practice framework can be instructive in helping researchers account for context beyond domain. Despite the fact that the study population came from one domain, the specific communities of practice in which each participant worked were related to variations in personal epistemologies. The types of companies, participants' titles, and the projects they undertook varied widely, as did their roles in the companies, with whom they interacted, and how they interacted with others. Those variations in their contexts had important implications for their personal epistemologies. 


\subsection{Epistemic Practices}

There is a small but growing body of literature providing evidence of the need to examine doing (or action) in relationship to personal epistemology. Task and strategy knowledge (Barzilai \& Zohar, 2014), epistemic activities (Hammer \& Elby, 2002; Rosenberg, Hammer, \& Phelan, 2006); and processes of achieving epistemic aims (Chinn et al., 2011) are all previously suggested lines of research that support the need to focus on practice. The relationships between "epistemic activities" and dimensions of PE, including sources of knowledge, have been recognized (Hammer \& Elby, 2002; Rosenberg, Hammer, \& Phelan, 2006), but metacognitive knowledge about activities and tasks is not commonly included in personal epistemology research (Barzilai \& Zohar, 2014). Furthermore, just as our definition of context differs from prior PE research, so too does our focus on epistemic practices diverge from prior research on action.

Epistemic practices are "procedural areas of action involved in the gathering, constitution, and implementation of knowledge and information" (Calvert-Minor, 2011, p.355). They are a key component of context in our framework. As recognized in the communities of practice framework, practices are inextricable from identity and knowledge (Wenger, 1998). The communities of practice literature has not dealt with the concept of epistemology to a large extent (or personal epistemology at all), but knowledge is a central facet of the framework, and the framework accounts for many concepts identified as metacognitive features of PE by Barzilai and Zohar (2014), including strategies, tasks, and experiences. We contend that findings from communities of practice can be extended to posit that practices are bound up not only with knowledge and identity, but also with personal epistemology.

In our empirical research, we have found participants' work contexts determine their epistemic practices. Our data display a diverse and complicated variety of ways that work contexts interact with epistemic practices. The type of company and the participants' roles therein provided wide variation in epistemic practices. Not only that, we observed that understanding of epistemic practices was further complicated by the fact that participants were answering interview questions on three different levels: what they think they do, what they think they should do, and what they think others do (Beddoes, Montfort, \& Brown, 2017). These differing epistemic practices (determined by context) then shaped identities and personal epistemologies.

\subsection{Identity}

In PE research, identity has been almost wholly ignored; however, Schachter and Rich (2011) have argued that identity is a vitally important concept for education researchers and practitioners. Following them, we define identity as:

[A]n individual's dynamic self-understandings and self-definitions used to structure, direct, give meaning to and present the self, that are negotiated intra- and interpersonally across the lifespan within sociocultural contexts, along with the psychosocial processes, meaning-systems, practices and structures that regulate their continued development. (p. 223)

This definition of identity aligns with the communities of practice framework because it 
highlights that identities are: 1) related to meaning systems, 2) related to practices, and 3) developed within sociocultural contexts. Within communities of practice, identities are lived, social, and learning processes (Wenger, 1998, p. 163). As Wenger (1998) contends "a community of practice is a field of possible trajectories and thus the proposal of an identity" (p. 156) and "our identities are rich and complex because they are produced within the rich and complex set of relations of practice" (p. 162).

The lack of attention to identity considerations in PE research is problematic because we observed that participants' epistemic practices were tied to how participants understood themselves and made meaning out of their work in the context of their community of practice, highlighting all of the complexity captured in Schachter \& Rich's (2011) definition above. Our participants' identities were related to their trajectories of participation in their communities of practice. In the CoP framework, there are a variety of ways in which one can exist in relation to the community. Peripheral and marginal participation at the edges, core participation in the center, and participation through brokering between different communities are the major modes of participation that shape community members' identities. We observed that participants' epistemic practices influenced their trajectories of participation and, consequently, their identities.

\subsection{Personal Epistemology}

As discussed in the overview of personal epistemology research above, dimensionality, and the interdependence of dimensions, has been a leading topic of interest in PE research (Bråten et al., 2011; Hofer, 2000). The authentic, practice-based framework presented here supports their interdependence. Many of our interview protocol questions were based on the four commonly utilized dimensions (source, structure, certainty, justification). Attempts to analyze the data revealed that dimensions of participants' personal epistemologies were heavily intertwined with other dimensions.

The focus on epistemic practices suggested strong interrelations among some dimensions of personal epistemology because the epistemic practices related to the acquisition of knowledge were undergirded by a more complicated network of personal epistemological beliefs than would be first assumed or is typically recognized by personal epistemology researchers. Beliefs about the source of knowledge were unavoidably tied to beliefs spanning the other dimensions of personal epistemology (certainty, justification, structure), even though in epistemology research they are often treated separately. For example, beliefs about the scientific method generating useful predictions from repeated observations were clearly related to the source of knowledge, but they also required certain assumptions about the structure and nature of knowledge and certainty: knowledge must consist of causal relationships that span across contexts, and reliable levels of certainty must be attainable through repeated observations.

Furthermore, while dimensions have guided much PE research, the issue of directionality has not featured prominently. The final arc in the framework connects personal epistemology back to context. This is intended to indicate that PE can affect perceptions of context. One's response to a situation can be shaped by her/his own perceptions (rather than an idealized 
"objective" description of the situation or a researcher's perceptions). The stances taken and the issues perceived simultaneously inform and are informed by the participants' personal epistemologies. Researchers are therefore caught in what we have labeled a hermeneutic bind (Beddoes, Montfort, \& Brown, 2017) because they must interpret participants' epistemological stances through the lens of the contexts that are themselves shaped by those stances. Stances on sources of knowledge were particularly notable in this regard. For instance, participants were asked to agree or disagree with the statement, "The source of most of my knowledge is authorities and experts." Participants who agreed with this statement did so for very different reasons. Context appeared to both shape and be shaped by the participants' personal epistemologies. Participants may be in systems where they are contextually limited to basic epistemological practices, and then their reliance on those practices is used as evidence to support the need to limit their practices.

\section{Discussion}

Described above is an empirically-inspired and theoretically grounded framework for researchers interested in advancing PE research in ways that address limitations of heretofore dominant approaches, namely a lack of accountability for context, authentic practices, and identity. Based on empirical research, we suggest that accounting for the ways authentic contexts, epistemic practices, and identities influence personal epistemologies is fundamentally vital for advancing understandings of the complexities of PE. The framework accounts for the authentic contexts in which people live and work, rather than utilizing the term "context" to refer to the topic of an interview or survey question.

The framework introduces communities of practice to the PE research landscape and demonstrates how it can help contextualize PE research. Unlike PE research, scholarship on communities of practice has a long tradition of examining the relationships between practices, identity, knowledge and learning. By situating PE research within authentic communities of practice, researchers would gain more accurate and nuanced understandings of the complexities and subtleties of PE. Furthermore, it has been argued that expanding the range of variables considered in PE research would increase the predictive value of the construct (Chinn et al., 2011).

While a thorough presentation of the data that led to development of the framework is beyond the scope of this article, a brief example can reveal connections between the components of our framework. The example is based on a newly hired engineer we will call Melissa. She works for a city port as an Environmental Remediation Specialist. To best elucidate the explanatory power of our framework we will begin by describing one element of Melissa's personal epistemology as revealed in focused interviews and then work clockwise through the elements in Figure 1 to demonstrate how each relates to and is therefore necessary to understand Melissa's personal epistemology.

Over many interviews and in reference to many different circumstances Melissa took the stance that the source of knowledge and certainty is authority. She described the source of her knowledge by saying, "I usually find stuff out because someone tells me 'this is how it is.' Like a professor, or in a review paper, or EPA is like, 'this is how we're going to handle 
this situation."' She associates this authority primarily with experience or research, which she counts as a particularly valid kind of experience. She said, "If it's in the code it's in there for a reason. It doesn't matter if I think it's true because someone smarter than me figured it out," and says that what ultimately makes something true is that, "someone did research and figured it out. They can back it up. It's been done before." In most personal epistemology research, this would be considered a naïve stance because it cedes authority for determining truth and creating knowledge to idealized, special agents. Indeed, this finding is even more robust than many previous studies because it is based on Melissa's stances in response to multiple questions framed in multiple contexts of her work: it would be reasonable based on existing models of personal epistemology to claim that Melissa naively depended on authorities to determine the truth of knowledge claims and deliver her knowledge to her.

In the authentic, practice-based framework, however, Melissa's stances take on different meanings. First, consider her context. Melissa works primarily with cleaning up soils that have become contaminated by spills, illegal dumping, leaking underground storage tanks or flowing water over the last few decades. The contamination is invisible, and, as Melissa says, "it doesn't sit in geometrically perfect shapes in the ground or in the water." Melissa and her colleagues rarely know exactly where the contaminated soil is, and therefore use careful sampling and statistics to define where it is most likely to be within a predefined margin of error. Additionally, the chemistry of soil and groundwater is such that "clean" and "contaminated" are not always clearly distinguishable. Local governmental bodies and special-purpose districts like Melissa's are tasked with maximizing their limited resources by only remediating contamination that is at a high enough level to pose a risk and is likely to come in contact with humans or ecosystems. In the United States, the Environmental Protection Agency is tasked with officially answering questions like "what margin of error is acceptable when removing contaminated soils" or "how can we objectively define 'clean'?" In the context of Melissa's work then, the EPA actually is granted special epistemological authority. Far from assuming the world to be simple and fully understood by some ideal agent, however, Melissa's reliance on the EPA reflects rather her participation in her community's nuanced response to complex, unpredictable problems requiring reliable and certain solutions.

Melissa's epistemic practices are the tangible traces of her participation in that community. Melissa's most common epistemic practice can be described as argument, or the intentional use of rhetoric or behaviors to influence another's perspective or decisions. When describing asking questions of her supervisor, for example, Melissa phrases it in terms of his "explaining what's wrong with my thinking." In one interview, she was explaining a difficult phone call in which she had to ask an engineer to make substantial changes to a design. She described it by saying, "One of our engineers sent us a grading plan and we had to send it back, well I had to send it back and tell him it was not what we wanted, and that was really awkward. The guy had like 40 years of experience on me and he was like, 'well this is the best way' and I was like, 'Well, no, it's not how we want it done'." When the interviewer clarified, "so you had to call him and tell him he did it wrong?" she responded, 
"yeah, well we just had to ask him to do it a different way." In simplistic, authority-based epistemologies the engineers' design would easily be considered "wrong" because it broke with established practice, and did not meet the project specifications. Melissa's description of the event, however, focuses much more heavily on the discussion of the event, culminating in her convincing the engineer to change his design. Melissa's epistemic practice of arguing (as contrasted to other participants' emphasis on "figuring out," "calculating," "checking" or "looking up") again makes more sense within her context of uncertainty governed by mutually agreed definitions. Although the EPA is the ultimate authority and regulator, "every single site is completely different. You could have all the same contaminants as the site next door but you're probably going to have a different source, or maybe a different type of soil or.... you're always trying to figure out a better way to do it." Melissa's work exists in the interstices between the EPA's authority and the unforeseen circumstances of any particular site, and therefore interpretation and argument are natural epistemic practices for someone with her personal epistemology in her context.

The data analyzed for this study was not collected with the intention of describing the participants' identities, but even without that intent, it is clear that some elements of Melissa's sense of self and identity are deeply entwined with her experience of her context and epistemic practices, and therefore with her personal epistemology. When Melissa discusses certainty or knowing, she is often talking about a certainty-that-the-environment-will-not-be-harmed, or knowing-that-the-public-is-safe. How much certainty is necessary, possible, or ideal in these situations depends strongly on how one understands one's role in the world as protector, consumer, citizen, or engineer. Melissa's epistemic practices of argumentation and interpretation directly depend on her identity within her community of practice because her effectiveness is shaped by her role relative to others. In the example of the grading plan, Melissa's job was to communicate required changes to the design engineer. The engineer's " 40 years of experience" and Melissa's lack of comparable experience effectively bounded Melissa's choices because, relative to the engineer, her interpretation of quality and technical details in grading design would be discredited. In this way, her characteristic epistemic practice of argumentation both defined her identity (her relative experience in design would not have been relative had the interaction been framed in terms of "clarifying requirements," for example, rather than interpretation and argumentation) and was defined by it.

Finally, we note that we have only explained a few potential interrelations between the elements of the framework in Melissa's case. It is unclear, for example, if Melissa's experience of her work context is colored by her personal epistemology, or if that work context has shaped her personal epistemology. Melissa justified her knowledge based on its source (research, repetition or legal authority), and chose the source of her knowledge based on its rhetorical validity with the audience she was considering (epistemic practices). Melissa's preferred level of certainty similarly depended on the audience, source and justification of her knowledge. In this way, the dimensions of Melissa's personal epistemology (Source of Knowledge, Justification, Certainty of Knowing) were closely interrelated with each other, and with her context, epistemic practices and identity within her 
community of practice. One of our goals with this framework is to highlight such complex interrelations of uncertain causal direction because they underscore the need to consider personal epistemology within a richer framework.

\section{Research Horizons and Methodological Considerations}

\subsection{Research Horizons}

Each component of the framework offers questions to guide future research. For example, because so little attention has been given to authentic, lived context, research horizons related to this topic are vast. Promising questions include: How does the context in which a person actually works shape his/her epistemic practices? In addition to the relationships in the framework, through what other mechanisms does context shape PE? To what extent do communities of practice vary within domains, and how does that variation in turn produce different epistemic practices? What new variables and trajectories of development emerge when authentic context becomes central to PE research? What is gained from comparative examinations of the relationship between context and epistemic practices across different domains? What can authentic contexts tell us about the relationships between metacognitive experiences and PE?

Likewise, the dearth of attention to authentic contexts means that authentic epistemic practices have not been accounted for in PE research, leaving numerous open questions about the relationships between epistemic practices and personal epistemologies. A far from exhaustive list includes: Through what mechanisms do epistemic practices shape identity and ultimately PE? What patterns in relationships between epistemic practices and identities within communities of practice can be identified? When, how, in what ways, and under what circumstances do certain epistemic practices lead to certain identities and PEs? In what ways does accounting for epistemic practices support prior research on epistemic tasks, activities, and goals? In what ways does accounting for epistemic practices challenge prior research on epistemic tasks, activities, and goals?

As far as identity, the most important research horizon suggested by our findings is to characterize the relationship between epistemic practices and identities and to characterize the relationships between identities within a community of practice and PE. What types of practices are associated with what types of identities? In what ways and under what circumstances do those identities shape PE? Are there ways in which identities are associated with contexts and epistemic practices that can help explain the gendering of certain fields?

The proposed framework suggests two additional important advances for the construct of PE related to directionality and dimensionality. First, the framework suggests that investigating the directionality of relationships between PE and other components of context may be valuable. Most prior research has been concerned with correlations between PE and other variables, but not the directionality of those correlations. The framework suggests that in fact directionality is an important part of understanding personal epistemologies. Future research could advance understanding of PE by exploring in what ways and to what extent $\mathrm{PE}$ influences identities, context and epistemic practices. Additionally, in different contexts, does 
the influence of certain components in the framework flow in directions other than those we observed in our research? Only through better understanding of directionality of influence for the various components can better measurement or prediction be facilitated.

Second, the framework suggests that better understanding of the dimensions that comprise PE and of the interrelations among those dimensions is much needed. Attention to authentic context may produce new understandings of the dimensions that comprise PE and the ways in which those dimensions are independent or interrelated. Can emergent dimensions be identified through attention to the authentic components identified in the framework? In what ways, under what circumstances, and from what epistemic practices do dimensions arise, and to what extent are dimensions independent or interrelated? Additionally, to what extent are the four traditional dimensions (source, structure, certainty, justification) useful in explaining PEs in authentic contexts? In other words, given how people talk about their own personal epistemologies, to what extent is the continued use of these four separate dimensions justified? (How) does each align, or not, with epistemic practices and ways in which people authentically work?

\subsection{Methodological Considerations}

This framework and the research that led to its development raise five methodological issues of significance to the area of PE research. First, most of the questions posed above cannot, at this point, be adequately addressed through surveys or quantitative questionnaires. The practice-based framework proposed herein adds fundamentally new components for PE research, and in the course of investigating those components research will likely produce emergent themes requiring grounded theory analyses. It was only through in-depth, longitudinal interviews that many of the limitations of current PE research were revealed. Others have likewise emphasized the need for qualitative interviews in order to understand PE (Chinn et al., 2011; Elby \& Hammer, 2001). Quantitative data and written surveys do not lend themselves to grounded theory or emergent themes. Qualitative interviews provide fuller, deeper, and more detailed descriptions than quantitative, closed-answer, or written surveys (Singleton \& Straits, 2010; Weiss, 1994). In-depth interviews allow researchers to learn about participants' thoughts, perceptions, and interpretations in ways that allow insight into their subjectivities (Patton, 2002; Weiss, 1994). In-depth interviews allow for salient issues to emerge during the course of the study in ways that closed-answer surveys cannot when the range of issues is already prescribed, making them particularly well suited to grounded theory analyses (Charmaz, 2006), which will be needed to answer many of the questions identified above. Further, ethnographic observations of authentic contexts are needed in addition to interviews, as they can produce insights participants themselves are not able to report in interviews, for a variety of reasons. In-depth qualitative interviews and ethnographic observations can then be used to identify variables and issues and frame hypotheses for subsequent quantitative research (Weiss, 1994).

Second, our empirical research has also revealed that the interviewer is a key consideration when researching personal epistemologies in authentic contexts. The interviewing and observation skills and knowledge of the researcher are fundamentally linked to the data 
captured. The most accurate and nuanced data will be collected by researchers who have an understanding of the context and can formulate appropriate follow-up questions when and where they are needed. For example, we found that many of the complexities emergent in our data required technical engineering knowledge to be made sense of.

Third, longitudinal studies are needed in order to fully address many of the suggested research questions. Longitudinal studies would allow researchers to begin to develop better understandings of how epistemic practices, identities, and personal epistemologies change over the course of careers, processes involved in those changes, and how the three are related. For example: If early career engineers do not see themselves as sources of knowledge, but they come to see themselves as sources of knowledge later in their careers, how does that happen? How might those processes be actively directed in certain ways to achieve desired epistemic practices in a given context?

A fourth methodological consideration concerns the sites and populations of research. The framework suggests additions to both are greatly needed, namely real-world settings and adults. PE research has been characterized almost exclusively by student populations in education settings, leaving a significant gap in our understanding of how PE functions in relation to real-world contexts of adults. The focus on education settings and students explains many features of PE research, such as operationalizing domain as discipline and context as topic, or epistemic task research, rather than an authentic epistemic practice carried out as part of an adult's job.

Fifth, answering questions such as those posed above will entail a willingness to deal with the messy realities of social science research (Fay, 1996; Law, 2004) to a much greater extent than has previously been seen in PE studies. It is worth a moment to situate this discussion more broadly within the history of psychology. The lack of context in early PE research, as well as the lack of specificity related to context even in the "resources" approach, reflects the history of a field that has systematically sought to exclude context from experimental research. In order to gain disciplinary prestige, psychology has, since its beginnings, vied to emulate the methods of the "hard sciences" and acquire the aura of "objectivity" commonly granted the hard sciences (Sherif, 1987). Essential to such efforts has been a desire to exclude subjects' sociocultural positioning and the messiness of everyday life, and to relegate important components of identity to "variables" (Sherif, 1987). As we have argued in this article however, it is precisely those components that are required in order to advance PE research. For such advances to be realized, authors, reviewers, and editors will likely need to confront entrenched disciplinary methodological norms.

\section{Conclusion}

Over the course of developing, conducting, and analyzing interviews to examine the personal epistemologies of engineering college students and practicing engineers, we struggled to make meaning and sense out of the interviews. Using common PE categories and questions proved problematic in numerous ways. Within our research team, it was difficult to have one person report findings on any individual component of $\mathrm{PE}$ because so much other information was needed that related to other components. Patterns of similarity could easily be recast as 
differences if certain circumstances or nuances of context were ignored. Moreover, within a single interview, across the longitudinal interviews from one participant, and among interviews from different participants, there seemed few patterns, generalizations, or claims that could be made about engineers' or engineering students' personal epistemologies. What did emerge, however, was a recognition that if any sense was to be made of their responses, it had to include deep and broad understanding of the participants' contexts and experiences that were shaping their answers. The authentic, practice-based framework laid out in this article is a result of those experiences. In sum, the framework conveys the idea that PE research must account for authentic contexts, communities of (epistemic) practice, and identities. Broadening PE research in this manner will allow for more robust, accurate, and nuanced understanding of individuals' and communities' personal epistemologies.

\section{Acknowledgments}

This material is based upon work supported by the National Science Foundation under Grant EEC \#1361229. Any opinions, findings, and conclusions or recommendations expressed in this material are those of the authors and do not necessarily reflect the views of the National Science Foundation. We thank our study participants for sharing their time and thoughts with us.

\section{References}

Barzilai, S., \& Zohar, A. (2014). Reconsidering Personal Epistemology as Metacognition: A Multifaceted Approach to the Analysis of Epistemic Thinking. Educational Psychologist, 49(1), 13-35. https://doi.org/10.1080/00461520.2013.863265

Baxter Magolda, M. B. (1992). Knowing and Reasoning in College: Gender-related Patterns in Students' Intellectual Development. San Francisco, CA: Jossey-Bass.

Beddoes, K., Montfort, D., \& Brown, S. (2017). Squaring Philosophy of Engineering with Personal Epistemologies Research. In D.M. Michelfelder, B. Newberry \& Q. Zhu (Eds.), Philosophy and Engineering: Exploring Boundaries, Expanding Connections (pp. 23-41). Cham, Switzerland: Springer. https://doi.org/10.1007/978-3-319-45193-0_3

Beddoes, K., Montfort, D., \& Brown, S. (2015). Epistemological Foundations of Global Competencies. Presented at the American Society for Engineering Education Annual Conference, Seattle, WA.

Belenky, M. F., Clinchy, B. M., Goldberger, N. R., \& Tarule, J. M. (1986). Women's Ways of Knowing: The Development of Self, Voice and Mind. New York, NY: Basic Books.

Bråten, I., Britt, M. A., Strømsø, H. I., \& Rouet, J.-F. (2011). The Role of Epistemic Beliefs in the Comprehension of Multiple Expository Texts: Toward an Integrated Model. Educational Psychologist, 46(1), 48-70. https://doi.org/10.1080/00461520.2011.538647

Bråten, I., Gil, L., Strømsø, H. I., \& Vidal-Abarca, E. (2009). Personal epistemology across cultures: Exploring Norwegian and Spanish university students' epistemic beliefs about climate change. Social Psychology of Education, 12(4), 529-560. 
https://doi.org/10.1007/s11218-009-9097-z

Buehl, M. M. (2008). Assessing the Multidimensionality of Students' Epistemic Beliefs Across Diverse Cultures. In M. S. Khine (Ed.), Knowing, Knowledge and Beliefs: Epistemological Studies Across Diverse Cultures (pp. 65-112). New York, NY: Springer. https://doi.org/10.1007/978-1-4020-6596-5_4

Buehl, M. M., \& Alexander, P. (2005). Motivation and Performance Differences in Students' Domain-Specific Epistemological Belief Profiles. American Educational Research Journal, 42(4), 697-726. https://doi.org/10.3102/00028312042004697

Buehl, M. M., Alexander, P., \& Murphy, P. K. (2002). Beliefs about Schooled Knowledge: Domain Specific or Domain General? Contemporary Educational Psychology, 27(3), 415-449. https://doi.org/10.1006/ceps.2001.1103

Calvert-Minor, C. (2011). "Epistemological Communities" and the Problem of Epistemic Agency. Social Epistemology: A Journal of Knowledge, Culture and Policy, 25(4), 341-360.

https://doi.org/10.1080/02691728.2011.604443

Carberry, A., Ohland, M. W., \& Swan, C. (2010). A Pilot Validation Study of the Epistemological Beliefs Assessment for Engineering (EBAE): First-Year Engineering student beliefs. Presented at the American Society for Engineering Education Annual Conference, Louisville, KY.

Charmaz, K. (2006). Constructing Grounded Theory: A Practical Guide Through Qualitative Analysis. Thousand Oaks, CA: Sage.

Chinn, C. A., Buckland, L. A., \& Samarapungavan, A. (2011). Expanding the Dimensions of Epistemic Cognition: Arguments From Philosophy and Psychology. Educational Psychologist, 46(3), 141-167. https://doi.org/10.1080/00461520.2011.587722

DeBacker, T. K., Crowson, H. M., Beesley, A. D., Thoma, S. J., \& Hestevold, N. L. (2008). The challenge of measuring epistemic beliefs: An analysis of three self-report instruments. Journal of Experimental Education, 281-312. https://doi.org/10.3200/JEXE.76.3.281-314

diSessa, A. A., Elby, A., \& Hammer, D. (2002). J's epistemological stance and strategies. In G. M. Sinatra \& P. R. Pintrich (Eds.), Intentional Conceptual Change (pp. 238-290). Mahwah, NJ: Erlbaum.

Efklides, A. (2002). The systemic nature of metacognitive experiences: Feelings, judgments, and their interrelations. In P. Chambers, M. Izaute, \& P-J. Marescaux (Eds.), Metacognition: Process, Function, and Use (pp. 19-34). Dordrecht, The Netherlands: Kluwer Academic Publishers. https://doi.org/10.1007/978-1-4615-1099-4_2

Efklides, A. (2006). Metacognition and affect: What can metacognitive experiences tell us about the learning process? Educational Research Review, 1(1), 3-14. https://doi.org/10.1016/j.edurev.2005.11.001 
Efklides, A. (2008). Metacognition: Defining its facets and levels of functioning in relation to self-regulation and co-regulation. European Psychologist, 13(4), 277-287. https://doi.org/10.1027/1016-9040.13.4.277

Elby, A. (2001). Helping physics students learn how to learn. American Journal of Physics, 69(7), S54-S64. https://doi.org/10.1119/1.1377283

Elby, A., \& Hammer, D. (2001). On the substance of a sophisticated epistemology. Science Education, 85(4), 554-567. https://doi.org/10.1002/sce.1023

Fay, B. (1996). Contemporary Philosophy of Social Science. Cambridge, MA: Blackwell.

Flavell, J. H. (1979). Metacognition and cognitive monitoring. American Psychologist, 34(10), 906-911. https://doi.org/10.1037/0003-066X.34.10.906

Franco, G. M., Muis, K. R., Kendeou, P., Ranellucci, J., Sampasivam, L., \& Wang, X. (2012). Examining the influences of epistemic beliefs and knowledge representations on cognitive processing and conceptual change when learning physics. Learning and Instruction, 22(1), 62-77. https://doi.org/10.1016/j.learninstruc.2011.06.003

Greene, J. A., Torney-Purta, J., \& Azevedo, R. (2010). Empirical evidence regarding relations among a model of epistemic and ontological cognition, academic performance, and educational level. Journal of Educational Psychology, 102(1), 234-255. https://doi.org/10.1037/a0017998

Hammer, D., \& Elby, A. (2002). On the form of personal epistemology. In B. K. Hofer \& P. R. Pintrich (Eds.), Personal Epistemology: The Psychology of Beliefs about Knowledge and Knowing (pp. 169-190). New York, NY: Lawrence Erlbaum Associates.

Hammer, D., \& Elby, A. (2003). Tapping epistemological resources for learning physics. Journal of the Learning Sciences, 12(1), 53-90. https://doi.org/10.1207/S15327809JLS1201_3

Hofer, B. K. (2000). Dimensionality and disciplinary differences in personal epistemology. $\begin{array}{lll}\text { Contemporary Educational } & \text { Psychology, 25(4), }\end{array}$ https://doi.org/10.1006/ceps.1999.1026

Hofer, B. K. (2004). Paradigmatic approaches to personal epistemology. Educational Psychologist, 39(1), 1-3. https://doi.org/10.1207/s15326985ep3901_1

Hofer, B. K., \& Pintrich, P. R. (1997). The development of epistemological theories: beliefs about knowledge and knowing and their relation to learning. Review of Educational Research, 67(1), 88-140. https://doi.org/10.3102/00346543067001088

Hogan, K. (1999). Relating Students' Personal Frameworks for Science Learning to Their Cognition in Collaborative Contexts. Science Education, 83(1), 1-32. https://doi.org/10.1002/(SICI)1098-237X(199901)83:1<1::AID-SCE1 >3.0.CO;2-D

Jehng, J.-C. J., Johnson, S. D., \& Anderson, R. C. (1993). Schooling and students' epistemological beliefs about learning. Contemporary Educational Psychology, 18(1), 25-35. 
https://doi.org/10.1006/ceps.1993.1004

King, B., \& Magun-Jackson, S. (2009). Epistemological beliefs of engineering students. The Journal of Technology Studies, 35(2), 56-64. https://doi.org/10.21061/jots.v35i2.a.6

King, P. M., \& Kitchener, K. S. (1994). The Development of Reflective Judgment: Understanding the Promoting Intellectual Growth and Critical Thinking in Adolescents and Adults. San Francisco, CA: Jossey-Bass.

Koriat, A. (2007). Metacognition and consciousness. In P. D. Zelazo, M. Moscovitch, \& E. Thompson (Eds.), The Cambridge Handbook of Consciousness (pp. 289-325). Cambridge, U.K.: Cambridge University Press. https://doi.org/10.1017/CBO9780511816789.012

Kuhn, D., Cheney, R., \& Weinstock, M. (2000). The development of epistemological understanding. Cognitive Development, 309-328. https://doi.org/10.1016/S0885-2014(00)00030-7

Kuhn, D., \& Pearsall, S. (1998). Relations between metastrategic knowledge and strategic $\begin{array}{llll}\text { performance. } \quad \text { Cognitive } & \text { Development, } & \text { 13(2), }\end{array}$ https://doi.org/10.1016/S0885-2014(98)90040-5

Kuhn, D., \& Weinstock, M. (2002). What is epistemological thinking and why does it matter? In B. K. Hofer, \& P. R. Pintrich (Eds.), Personal Epistemology: The Psychology of Beliefs about Knowledge and Knowing (pp. 121-144). Mahwah, NJ: Erlbaum.

Lave, J., \& Wenger, E. (1991). Situated Learning: Legitimate Peripheral Participation. New York, NY: Cambridge University Press. https://doi.org/10.1017/CBO9780511815355

Law, J. (2004). After Method: Mess in Social Science Research. New York, NY: Routledge.

Limón Luque, M. (2003). The role of domain-specific knowledge in intentional conceptual change. In G. M. Sinatra \& P. R. Pintrich (Eds.), Intentional Conceptual Change (pp. 133-170). Mahwah, NJ: Erlbaum.

Lising, L., \& Elby, A. (2005). The impact of epistemology on learning: A case study from introductory physics. American Journal of Physics, 73(4), 372-382. https://doi.org/10.1119/1.1848115

Louca, L., Elby, A., Hammer, D., \& Kagey, T. (2004). Epistemological resources: Applying a new epistemological framework to science instruction. Educational Psychologist, 39(1), 57-68. https://doi.org/10.1207/s15326985ep3901_6

Mason, L. (2002). Developing epistemological thinking to foster conceptual change in different domains. In M. Limon \& L. Mason (Eds.), Reconsidering Conceptual Change: Issues in Theory and Practice (pp. 301-336). Dordrecht, The Netherlands: Kluwer Academic Publishers. https://doi.org/10.1007/0-306-47637-1_16

Montfort, D., Brown, S., \& Shinew, D. (2014). The personal epistemologies of civil engineering faculty. Journal of Engineering Education, 103(3), 388-416. https://doi.org/10.1002/jee.20050 
Muis, K. R., Bendixen, L. D., \& Haerle, F. C. (2006). Domain-Generality and Domain-Specificity in Personal Epistemology Research: Philosophical and Empirical Reflections in the Development of a Theoretical Framework. Educational Psychology Review, 18(1), 3-54. https://doi.org/10.1007/s10648-006-9003-6

Palmer, B., \& Marra, R. M. (2004). College student epistemological perspectives across knowledge domains: A proposed grounded theory. Higher Education, 47(3), 311-335. https://doi.org/10.1023/B:HIGH.0000016445.92289.f1

Pavelich, M. J., \& Moore, W. S. (1996). Measuring the Effect of Experiential Education Using the Perry Model. Journal of Engineering Education, 85(4), 287-292. https://doi.org/10.1002/j.2168-9830.1996.tb00247.x

Perry, W. G. (1970). Forms of Intellectual and Ethical Development in the College Years: A Scheme. New York, NY: Holt, Rinhart and Winston.

Rosenberg, S., Hammer, D., \& Phelan, J. (2006). Multiple epistemological coherences in an eighth-grade discussion of the rock cycle. Journal of the Learning Sciences, 15(2), 261-292. https://doi.org/10.1207/s15327809j1s1502_4

Sawyer, R.K. \& Greeno, J.G. (2009). Situativity and learning. In P. Robbins \& M. Aydede (Eds.), The Cambridge Handbook of Situated Cognition (pp. 347-367). Cambridge, MA. Cambridge University Press.

Schachter, E. P., \& Rich, Y. (2011). Identity Education: A Conceptual Framework for Educational Researchers and Practitioners. Educational Psychologist, 46(4), 222-238. https://doi.org/10.1080/00461520.2011.614509

Schatzki, T. R., Knorr Cetina, K., \& Von Savigny, E. (2001). The Practice Turn in Contemporary Theory. New York, NY: Routledge.

Schommer-Aikins, M. (2002). An evolving theoretical framework for an epistemological belief system. In B. K. Hofer \& P. R. Pintrich (Eds.), Personal Epistemology: The Psychology of Beliefs about Knowledge and Knowing (pp. 103-118). Mahwah, NJ: Erlbaum.

Schommer-Aikins, M. (2004). Explaining the epistemological belief system: Introducing the embedded systemic model and coordinated research approach. Educational Psychologist, 39(1), 19-29. https://doi.org/10.1207/s15326985ep3901_3

Schommer, M. (1994). Synthesizing Epistemological Belief Research: Tentative Understandings and Provocative Confusions. Educational Psychology Review, 6(4), 293-319. https://doi.org/10.1007/BF02213418

Sherif, C. W. (1987). Bias in Psychology. In S. Harding (Ed.), Feminism \& Methodology (pp. 37-56). Bloomington: Indiana University Press.

Singleton, R., \& Straits, B. (2010). Approaches to Social Research (5th ed). New York, NY: Oxford University Press.

Stahl, E., \& Bromme, R. (2007). The CAEB: An instrument for measuring connotative 


\section{Macrothink}

International Journal of Learning and Development

aspects of epistemological beliefs. Learning and Instruction, 17(6), 773-785. https://doi.org/10.1016/j.learninstruc.2007.09.016

Trautwein, U., \& Lüdtke, O. (2007). Predicting global and topic-specific certainty beliefs: Domain-specificity and the role of the academic environment. British Journal of Educational Psychology, 77(4), 907-934. https://doi.org/10.1348/000709906X169012

Weiss, R. (1994). Learning from Strangers: The Art and Method of Qualitative Interview Studies. New York, NY: Free Press.

Wenger, E. (1998). Communities of Practice. New York: Cambridge University Press. https://doi.org/10.1017/CBO9780511803932

Wise, J. C., Lee, S. H., Litzinger, T., Marra, R. M., \& Palmer, B. (2004). A Report on a FourYear Longitudinal Study of Intellectual Development of Engineering Undergraduates. Journal of Adult Development, 11(2), 103-110. https://doi.org/10.1023/B:JADE.0000024543.83578.59

Wood, P., \& Kardash, C. (2002). Critical elements in the design and analysis of studies in epistemology. In B. K. Hofer \& P. R. Pintrich (Eds.), Personal Epistemology: The Psychology of Beliefs about Knowledge and Knowing (pp. 231-260). Mahwah, NJ: Erlbaum.

Yerdelen-Damar, S., Elby, A., \& Eryilmaz, A. (2012). Applying beliefs and resources frameworks to the psychometric analyses of an epistemology survey. Physical Review Special Topics-Physics Education Research, $\quad 8(1), \quad$ 1-10. https://doi.org/10.1103/PhysRevSTPER.8.010104

\section{Copyright Disclaimer}

Copyright for this article is retained by the author(s), with first publication rights granted to the journal.

This is an open-access article distributed under the terms and conditions of the Creative Commons Attribution license (http://creativecommons.org/licenses/by/4.0/). 